to determine the number needed to vaccinate (NNV) to prevent mortality from HAV. The total vaccine cost was also calculated. Baseline mortality and cost data from the US were used as an example.

Results 239 studies were identified using a defined search strategy. From those, 11 appeared to be relevant to the study and of these 7 were suitable for inclusion in the meta-analysis. The pooled OR for mortality risk in HAV superinfection of HCV infected persons was 7.23 (95\% CI 1.24 to 42.12 ) with significant heterogeneity $\left(I^{2}=56 \%\right.$, $\mathrm{p}=0.03$ ) between studies. Case-fatality rates are however low, and in the US at the last estimate (2007) the number of deaths from HAV in the general population was 34 per year $(0.2 / 1000000$ population). Using the pooled $\mathrm{OR}$ for mortality that translates to 1.4 deaths per 1000000 susceptible persons with HCV per year. The NNV to prevent 1 death per year is therefore 814849 assuming $90 \%$ vaccine uptake and $94.3 \%$ vaccine efficiency. The vaccine cost for this totals $\$ 162$ million, or $\$ 80.1$ million per death prevented per year.

Conclusion These data challenge the utility of routine HAV vaccination in HCV infected persons and its incorporation into clinical practice guidelines. HAV vaccination of all HCV infected persons in low incidence areas is likely to expose many individuals to an intervention that is of no direct benefit.

Competing interests None declared.

\section{PM0-154 PLASMA HBSAG LEVELS DECLINE WAS SIMILAR DURING SUBSEQUENT PEGYLATED INTERFERON AND NUCLEOS (T)IDE ANALOGUES TREATMENT IN CHRONIC HEPATITIS B PATIENTS}

doi:10.1136/gutjnl-2012-302514b.154

M J Bruce, M Horner, S Hughes, S Knighton, D Joshi, P M Harrison, K Agarwal, I Carey. * Institute of Liver Studies and Transplantation, King's College Hospital, London, UK

Introduction Pegylated interferon (Peg-IFN) therapy responses in chronic hepatitis B (CH-B) are associated with decline of $\mathrm{HBsAg}$ plasma levels (qHBsAg) $\left(>10 \%\right.$ in $\mathrm{HBeAg}-$ and $>0.5 \log _{10} \mathrm{IU} / \mathrm{ml}$ in $\mathrm{HBeAg}+$ ) and HBV DNA decrease $>2 \log _{10} \mathrm{IU} / \mathrm{ml}$ during the first 6 months of therapy. In contrast, qHBsAg decline is less pronounced, but with sharper HBV DNA decline on therapy with nucleos(t)ide analogues (NA). The previous studies comparing qHBsAg and HBV DNA kinetics between Peg-IFN and NA treatments were performed on variable cohorts, but not on a monocentric single cohort of patients undergoing consecutively variable courses of therapy.

Aims To compare the kinetics of qHBsAg and HBV DNA levels before and during therapy; initially with Peg-IFN and then after at least a 6-month break (median 15 months) with subsequent NA therapy in the same cohort of CH-B patients.

Methods qHBsAg levels by Abbott ARCHITECT ${ }^{\circledR}$ assay and HBV DNA by real-time TaqMan PCR [both $\log _{10} \mathrm{IU} / \mathrm{ml}$ ] were quantified in serial samples at baseline, treatment week 12 (TW12), TW24, TW48. HBeAg loss/anti-HBe seroconversion were evaluated at the same time-points. All results are presented as medians.

Results Four Peg-IFN patients (20\%) achieved anti-HBe seroconversion, in contrast to only $1 \mathrm{NA}$ patient (5\%). At baseline, qHBsAg and HBV DNA levels were similar between Peg-IFN and NA (3.92 vs 3.72 and 6.21 vs 5.91). At TW12 and TW24, qHBsAg did not change in Peg-IFN and NA treatment (3.86 vs 3.68 and 3.57 vs 3.49 respectively), but HBV DNA dropped significantly during NA therapy only (4.55 vs 2.29 and 4.53 vs 1.23 , both $\mathrm{p}<0.01)$. At TW48, qHBsAg remained unchanged in both treatments (3.48 vs 3.46 ), but HBV DNA was undetectable in NA patients (0 vs 4.68, $\mathrm{p}<0.01$ ). Only NA therapy achieved complete virological response (HBV
DNA $<20 \mathrm{IU} / \mathrm{ml})$ in six patients $(30 \%)$ at TW12, 8 patients $(40 \%)$ at TW24 and 15 patients $(75 \%)$ at TW48 (all $\mathrm{p}<0.05)$. Only patients with qHBsAg decline by $>0.5 \log _{10} \mathrm{IU} / \mathrm{ml}$ by TW24 achieved anti-HBe seroconversion in both treatments.

Conclusion $\mathrm{HBsAg}$ decline $>0.5 \log _{10} \mathrm{IU} / \mathrm{ml}$ by TW24 was predictive of anti-HBe seroconversion irrespective of therapeutic approach Although plasma HBsAg kinetics was similar during Peg-IFN or NA therapy in Peg-IFN non-responders, HBV DNA viral load declined significantly only during NA therapy from TW12 in the same cohort of $\mathrm{CH}-\mathrm{B}$ patients.

Competing interests M Bruce: None declared, M Horner: None declared, S Hughes: None declared, S Knighton: None declared, D Joshi: None declared, P Harrison: None declared, K Agarwal: None declared, I Carey grant/research support from: BMS, Gilea.

\section{PM0-155 LOW PRE-TREATMENT HBSAG PLASMA LEVELS, ON THERAPY HBSAG LEVELS DECLINE AND IP-10 CONCENTRATIONS INCREASE PREDICT RESPONSE TO TREATMENT IN TOLERANT CHILDREN WITH CHRONIC HEPATITIS B}

doi:10.1136/gutjnl-2012-302514b.155

I Carey, ${ }^{*}$ M J Bruce, M Hussain, M Horner, S Bansal, D Vergani, G Mieli-Vergani. Institute of Liver Studies and Transplantation, King's College Hospital, London, UK

Introduction Changes in HBsAg plasma levels during antiviral therapy with pegylated interferon (IFN) predict response in chronic hepatitis $\mathrm{B}(\mathrm{CH}-\mathrm{B})$. High baseline plasma levels of inducible interferon- $\boldsymbol{\gamma}$ protein 10 (IP-10) predicted HBsAg loss in CH-B adults patients on nucles(t)ide analogues (NA) therapy. No data are available on the relationship between IP-10 and HBsAg plasma levels in children with infancy-acquired $\mathrm{CH}-\mathrm{B}$ on combination therapy.

Aims To investigate whether baseline plasma IP-10 levels and their changes during therapy can help to predict HBsAg loss in children with infancy-acquired $\mathrm{CH}-\mathrm{B}$ on combination therapy with lamivudine (LAM) and IFN- $\alpha$

Methods Patients: 23 children (eight males, median age $10.2 \mathrm{yrs}$ ) with infancy-acquired $\mathrm{CH}-\mathrm{B}$ (all $\mathrm{HBeAg}+$ ), treated for 52 weeks [lead-in LAM (3 mg/kg/d) for 9 weeks; LAM plus IFN- $\alpha\left(5 \mathrm{MU} / \mathrm{m}^{2}\right.$ TIW) from week 9 for 44 weeks], were divided according to treatment response: five responders $(\mathrm{R}=$ anti-HBs seroconversion $)$ and 18 non-responders (NR).

Methods Plasma IP-10, HBsAg and AST levels were measured in serial samples before (treatment week 0, TW0), during (TW9, TW28, TW52) and after (follow-up week, FUW24) therapy by ELISA $[\mathrm{pg} / \mathrm{ml}]$, Abbott ARCHITECT ${ }^{\circledR}$ assay $\left[\log _{10} \mathrm{IU} / \mathrm{ml}\right]$ and AutoAnalyser [IU/1]. The results are presented median.

Results Baseline IP-10 levels were similar in R and NR (123 vs 99, $\mathrm{p}=0.4$ ), but increased significantly in R than NR at TW28 (220 vs $79, \mathrm{p}=0.04$ ). Baseline HBsAg levels were lower in $\mathrm{R}$ than $\mathrm{NR}$ (4.36 vs 4.74, $\mathrm{p}=0.02$ ), but similar in R and NR at TW9 (4.34 vs 4.66, $\mathrm{p}=0.1$ ) and markedly lower in R than NR during IFN add-on therapy and therapy follow-up (TW28: 2.34 vs 4.33; TW52: 0 vs 4.08 and FUW24: 0 vs 4.51; $p<0.01$ for all). Baseline AST levels were similar in $\mathrm{R}$ and NR ( 29 vs $31, \mathrm{p}=0.6$ ) and tended to be higher in $\mathrm{R}$ than NR at TW28 (47 vs 32, $\mathrm{p}=0.07$ ). At TW28, there was an inverse correlation between IP-10 and HBsAg levels $(r=-0.45, p=0.03)$, but no correlation with AST.

Conclusion Low baseline HBsAg levels, HBsAg plasma levels decline and IP-10 concentrations increase during interferon add-on at TW28 predict HBsAg loss and response to therapy in tolerant children with $\mathrm{CH}-\mathrm{B}$.

Competing interests I Carey grant/research support from: BMS, Gilead, M Bruce: None declared, M Hussain: None declared, M Horner: None declared, S Bansal: None declared, D Vergani: None declared, G Mieli-Vergani: None declared. 